\title{
WYKORZYSTANIE TECHNIKI ŚLEDZENIA PROMIENIA DO MODELOWANIA WYSOKOTEMPERATUROWYCH UKŁADÓW HELIOENERGETYCZNYCH
}

\begin{abstract}
W niniejszym artykule przedstawiono wyniki symulacji komputerowych przeprowadzonych w Katedrze Zrównoważonego Rozwoju Energetycznego na Wydziale Energetyki i Paliw AGH w Krakowie. Wykonane prace dotyczą układu helioenergetycznego koncentrującego promieniowanie słoneczne i składającego się z dwóch elementów skupiających oraz elementu będącego odbiornikiem ciepła wysokotemperaturowego. Ze względu na fakt, iż w układzie powstają dwa różne ogniska skupionych promieni, głównym celem badań było określenie najlepszego umiejscowienia absorbera. Przy wyborze odpowiedniego usytuowania kierowano się ilością absorbowanej przez odbiornik energii świetlnej oraz ograniczoną wytrzymałością materiałową odbiornika - rozkładem natężenia promieniowania na jego powierzchni. Do przeprowadzenia opisanych symulacji wykorzystano zmodyfikowaną metodę śledzenia promieni, która zazwyczaj wykorzystywana jest do tworzenia realistycznych obrazów w grafice komputerowej. W badaniach oparto się na zmodyfikowanej o algorytm Monte Carlo metodzie, gdzie śledzone są wszystkie promienie wychodzące od źródła światła i znajdujące się na scenie optycznej, a nie tylko te, które trafiają do obserwatora jak to ma miejsce w przypadku klasycznego śledzenia promieni. W wyniku przeprowadzonych symulacji wygenerowano mapy i wykresy rozkładu natężenia promieniowania absorbowanego przez powierzchnię odbiornika ciepła. Wykonane analizy pozwoliły wywnioskować, że w przypadku opisanej w artykule instalacji helioenergetycznej najlepszym rozwiązaniem jest umiejscowienie odbiornika ciepła o średnicy $18 \mathrm{~cm}$ w odległości $77 \mathrm{~cm}$ od powierzchni lustra skupiającego. Otrzymane dane mają posłużyć w kolejnych badaniach jako warunki brzegowe drugiego rzędu w symulacjach komputerowych opartych na technice numerycznej mechaniki płynów CFD.
\end{abstract}

Słowa kluczowe: śledzenie promieni, koncentrator promieniowania słonecznego, Światło skupione, TracePro, symulacje komputerowe

\footnotetext{
${ }^{1}$ Autor do korespondencji: Estera Bożek, AGH w Krakowie, Wydział Energetyki i Paliw, Katedra Zrównoważonego Rozwoju Energetycznego, Al. A. Mickiewicza 30, 30-059 Kraków, tel.0126173428, ebozek@agh.edu.pl

${ }^{2}$ Mariusz Filipowicz, AGH w Krakowie, Wydział Energetyki i Paliw, Katedra Zrównoważonego Rozwoju Energetycznego, Al. A. Mickiewicza 30, 30-059 Kraków
} 


\section{Wstęp}

Obecnie w Europie i na Świecie prowadzone są działania zmierzające do coraz większego wykorzystania odnawialnych źródeł energii. Jest to spowodowane m.in. Dyrektywami jakie nakłada na kraje członkowskie Unia Europejska, gdzie nakazuje się zmniejszanie zużycia energii, ochronę środowiska, redukcję emisji gazów cieplarnianych a także promowanie i zwiększanie udziału OZE w sektorze energetycznym. Jednakże nie tylko Dyrektywy i inne przepisy prawne przyczyniają się do rozwoju technologii opartych na odnawialnych źródłach, jest to spowodowane również indywidualnym dążeniem użytkowników energii do niezależności energetycznej, zmniejszania rachunków czy też utożsamiania się z ideą zrównoważonego rozwoju energetycznego. Dla małych i średnich obiektów (domy jedno- i wielorodzinne, szkoły, budynki użyteczności publicznej, itp.) energetyka słoneczna jest jedną z najwygodniejszych, najtańszych i najbezpieczniejszych form produkcji ciepła i prądu.

W Katedrze Zrównoważonego Rozwoju Energetycznego na AGH w Krakowie prowadzone są badania nad możliwościami wykorzystania mikro instalacji opartej na skoncentrowanym promieniowaniu słonecznym. Sprawdzono, że badany typ instalacji może służyć do:

generacji energii mechanicznej poprzez wykorzystanie silnika Stirlinga, energii elektrycznej przy zastosowaniu ogniw fotowoltaicznych (wyższe wydajności),

transportu wzmocnionego światła w światłowodach.

Planowane są również prace mające na celu wykorzystanie skupionego światła słonecznego do produkcji chłodu, a także przeprowadzenia procesu zgazowania biomasy [1]. Podstawowym problemem w tego typu instalacjach jest jednak odpowiednie zaprojektowanie geometrii układu koncentrującego oraz odbiorników wysokotemperaturowego ciepła, które muszą charakteryzować się wysoką sprawnością. Odpowiednim sposobem na projektowanie i testowanie instalacji w sposób stosunkowo tani i efektywny jest przeprowadzenie symulacji komputerowych. Na Świecie wykorzystuje się różne techniki symulacyjne w celu przeanalizowania propagacji światła w układach optycznych. Na przykład $\mathrm{w}$ pracy zaprezentowanej $\mathrm{w}$ [2] prowadzone są działania mające na celu zwiększanie efektywności rurowych kolektorów słonecznych. Natomiast w artykule [3] autor analizuje symulację układu świetlno-optycznego gdzie do oceny dokładności stosowanej metody wykorzystuje odbłyśnik. Również w Polsce prowadzone są podobne badania, np. takie jak przeprowadzone na Politechnice Warszawskiej opisane w [4] symulacje figury jasnych punktów, wykorzystywanej głównie do projektowania reflektorów.

W niniejszym artykule zaprezentowano wyniki symulacji układu koncentrującego promieniowanie słoneczne, których głównym celem było wyznaczenie miejsca, w którym powinien znajdować się odbiornik wysokotemperaturowego ciepła o określonych wymiarach, tak aby absorbował on jak największą 
ilość promieniowania i jednocześnie aby rozkład natężenia światła był w miarę równomierny.

\section{Stanowisko badawcze i metodyka}

\subsection{Opis rzeczywistego układu koncentrującego}

Modelowana instalacja helioenergetyczna znajduje się na dachu budynku Katedry Zrównoważonego Rozwoju Energetycznego na AGH w Krakowie rys.1. Szkice techniczne opisywanego urządzenia zaprezentowano na rysunku 2.

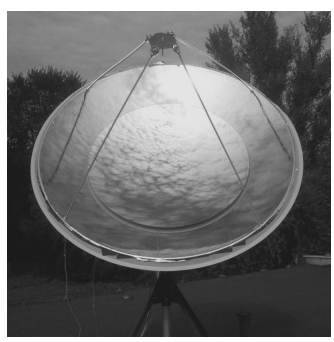

Rys. 1. Koncentrator promieniowania słonecznego na dachu Katedry ZRE na AGH w Krakowie. Widoczne są dwa elementy skupiające światło - lustro i talerz wyklejony folią refleksyjną [1]

Fig. 1. Solar radiation concentrator placed on the roof of Sustainable Energy Department building, AGH in Krakow. Two elements focusing lights are visible - mirror and bowl lined with reflective foil [1]

Instalacja skupiająca światło zbudowana jest z talerza paraboloidalnego o średnicy $1800 \mathrm{~mm}$ wyklejonego refleksyjną folią oraz osadzonego na nim lustra o nieco innej geometrii (średnica $1200 \mathrm{~mm}$ ). Lustro odsunięte jest od czaszy koncentratora o odległość $26 \mathrm{~mm}$ co w połączeniu z niewielką różnicą w geometrii obu elementów koncentrujących powoduje powstawanie dwóch ognisk skupionych promieni.

Urządzenie śledzi położenie słońca za pomocą algorytmu astronomicznego, dzięki czemu promienie słoneczne padają na koncentrator pod kątem prostym. Elementami wykonawczymi całej instalacji są dwa siłowniki liniowe obracające czaszą w dwóch płaszczyznach - azymutu i elewacji [1].

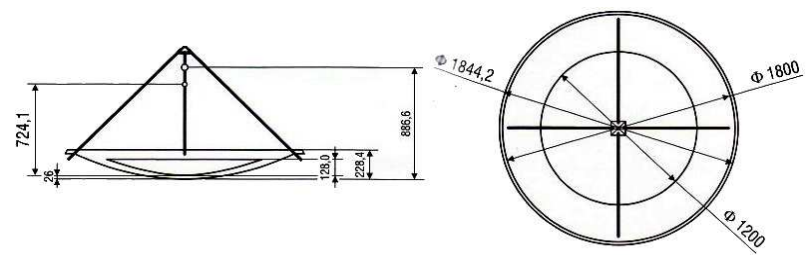

Rys. 2. Rysunki techniczne koncentratora [1]

Fig. 2. Technical drawing of solar concentrator [1] 


\subsection{Metodyka symulacji komputerowych}

Promieniowanie słoneczne jest niewidzialne, co sprawia, że projektowanie układów helioenergetycznych jest dość trudne. Symulacje komputerowe pozwalają przewidzieć drogę promieni. Jeszcze zanim nastąpi rzeczywista realizacja układu możliwe jest wskazanie miejsc gdzie następuje np. niechciane odbicie czy też wyznaczyć intensywność promieniowania w dowolnym miejscu układu, co czasem w trakcie badań rzeczywistego stanowiska badawczego jest niemożliwe.

W celu zbadania opisanego układu optycznego koncentrującego promieniowanie słoneczne wykorzystano oprogramowanie firmy Lambda Research o nazwie TracePro. Jest to narzędzie umożliwiające symulowanie propagacji światła i uwzględnia podstawowe zjawiska optyki takie jak absorpcja, odbicie, załamanie, dyfrakcja, rozpraszanie. Program wykorzystuje zmodyfikowaną technologię Ray Tracing opartą na metodzie Monte Carlo. Śledzenie odbywa się nieco inaczej niż w przypadku standardowego zastosowania metodyki w grafice komputerowej gdzie istotne są jedynie te promienie, które trafiają do oka obserwatora. W TracePro rozpatrywana jest droga wszystkich promieni wyemitowanych przez źródło światła. Zastosowana w algorytmie metoda Monte Carlo powoduje, że promienie emitowane są w sposób losowy z różnych punktów źródła światła.

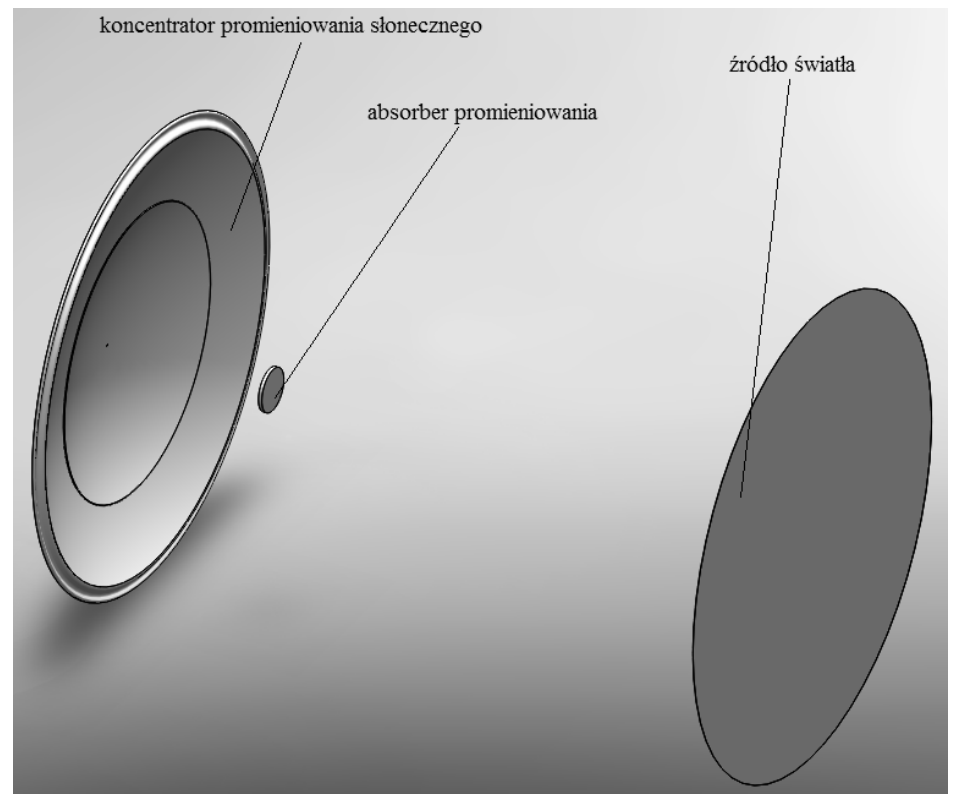

Rys. 3. Widok modelu bryłowego symulowanego układu wykonany w programie SolidWorks

Fig. 3. Solid model of the simulated system made in SolidWorks software 
Pierwszym krokiem w pracy z opisanym oprogramowaniem jest zaimportowanie wcześniej przygotowanego modelu bryłowego. Możliwe jest również wykonanie prostych brył bezpośrednio w TracePro. W pracach zaprezentowanych w niniejszym artykule do wykonania projektu posłużono się programem SolidWorks, gdzie wykonane zostały bryły: koncentratora (dwa elementy skupiające), odbiornika ciepła wysokotemperaturowego o średnicy $180 \mathrm{~mm}$ (absorber promieniowania) oraz źródła światła - model przedstawiono na rysunku 3.

Zaimportowanym bryłom nadano odpowiednie właściwości materiałowe i powierzchniowe. Jako materiał na czaszę koncentratora oraz odbiornik ciepła wybrano aluminium, natomiast dla lustra wybrany został jeden z rodzajów szkła wykorzystywany w optyce helioenergetycznej. Powierzchnia całego koncentratora określona została jako standardowe lustro o refleksyjności $90 \%$. Element absorbujący scharakteryzowano jako powierzchnię pomalowaną czarną farbą. Dla powierzchni symulującej źródło światła słonecznego wpisano zakres spektralny promieniowania od $0 \mathrm{~nm}$ do $1400 \mathrm{~nm}$. W badaniach układu zmieniano położenie odbiornika ciepła i generowano mapy rozkładu natężenia promieniowania na jego powierzchni.

$\mathrm{Na}$ rysunku 4 przedstawione jest okno programu TracePro z prześledzoną już drogą promieni. Dla takiego widoku, aby nie zaciemniać całego obrazu wygenerowano zaledwie 300 promieni. Natomiast w przypadku tworzenia map natężenia światła generowanych było 50000 promieni świetlnych.

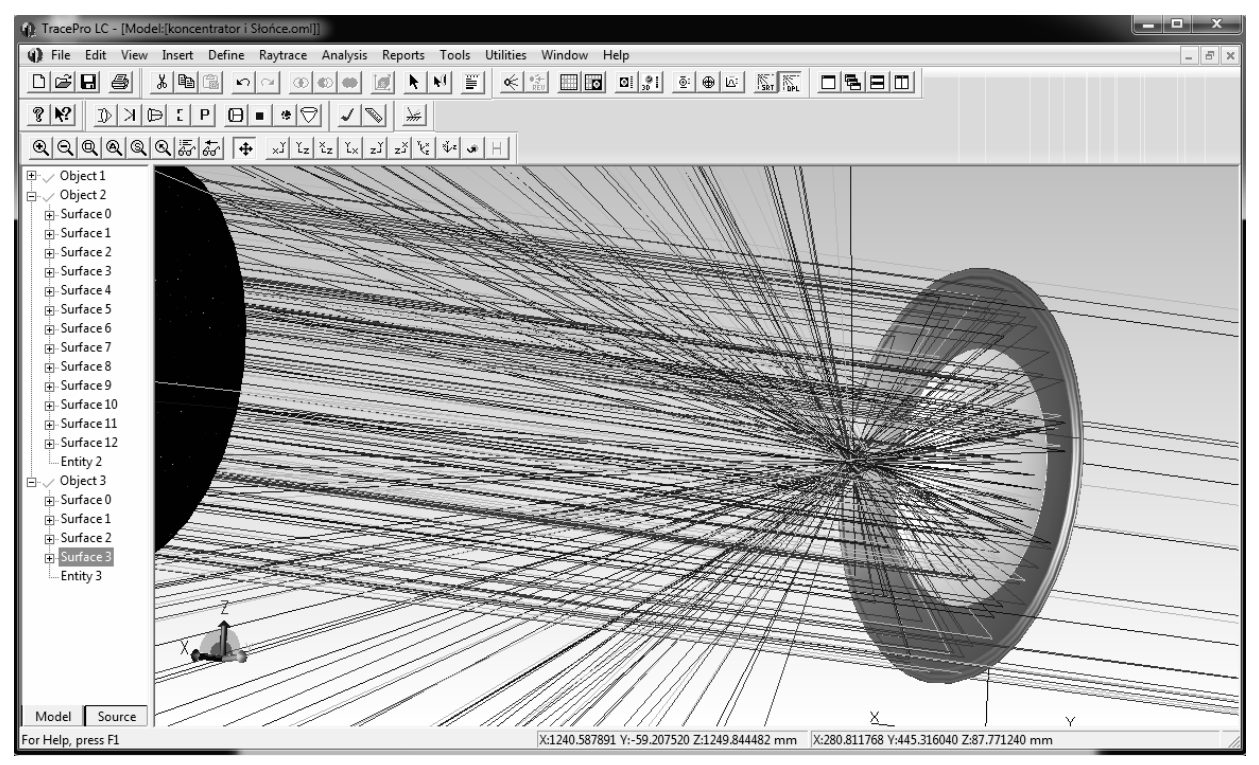

Rys. 4. Wynik symulacji układu koncentrującego - wygenerowane 300 promieni

Fig. 4. Simulation result of the focusing system - generated 300 rays 


\section{Wyniki symulacji}

Pierwszą symulację przeprowadzono bez odbiornika ciepła - na scenie optycznej znajdował się jedynie koncentrator promieniowania słonecznego i źródło światła. W wyniku wykonanych symulacji widać, że pojawiają się dwa ogniska skupienia promieni, jedno od talerza - F1 oraz drugie od lustra - F2 rys.5. Ponadto zauważyć można, że ogniska te są nieco rozmyte co jest spowodowane zjawiskiem aberracji chromatycznej. Zanim promienie zostaną odbite od refleksyjnego srebra w lustrze przechodzą przez warstwę szkła co powoduje pewne przesunięcie wychodzących promieni o różnych długościach fal (różne współczynniki załamania światła dla różnych długości fal z widma promieniowania słonecznego).

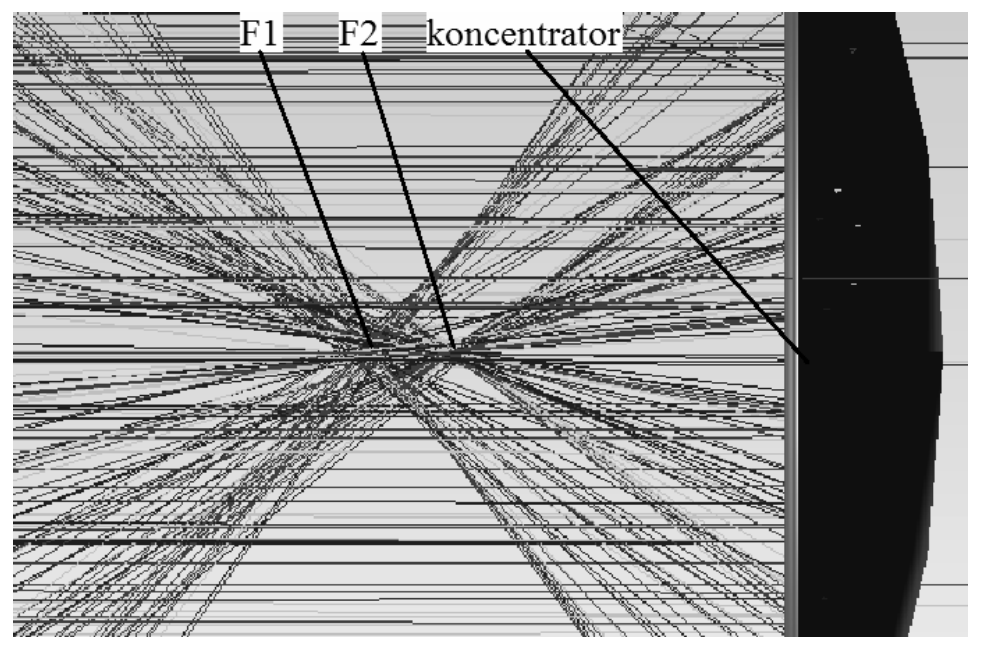

Rys. 5. Wynik symulacji z widocznymi dwoma ogniskami skupienia promieni F1 i F2

Fig. 5. Simulation results - two focal points are visible (F1, F2)

W kolejnym kroku do modelu wprowadzono odbiornik ciepła. Absorber ustawiany był w kilku wybranych miejscach w pobliżu ognisk:

w ognisku F1 znajdującym się w odległości $70 \mathrm{~cm}$ od powierzchni lustra, w odległości $60 \mathrm{~cm}$ od powierzchni lustra (przed ogniskiem F1), w odległości $59 \mathrm{~cm}$ od powierzchni lustra (przed ogniskiem F1), w odległości $75 \mathrm{~cm}$ od powierzchni lustra (między ogniskami), w odległości $76 \mathrm{~cm}$ od powierzchni lustra (między ogniskami), w odległości $77 \mathrm{~cm}$ od powierzchni lustra (między ogniskami).

W wyniku symulacji wygenerowano mapy natężenia promieniowania na absorberze oraz wykresy rozkładu tego natężenia $w$ dwóch osiach na powierzchni absorbera (pionowej i poziomej) - rys. 6 i rys. 7. 


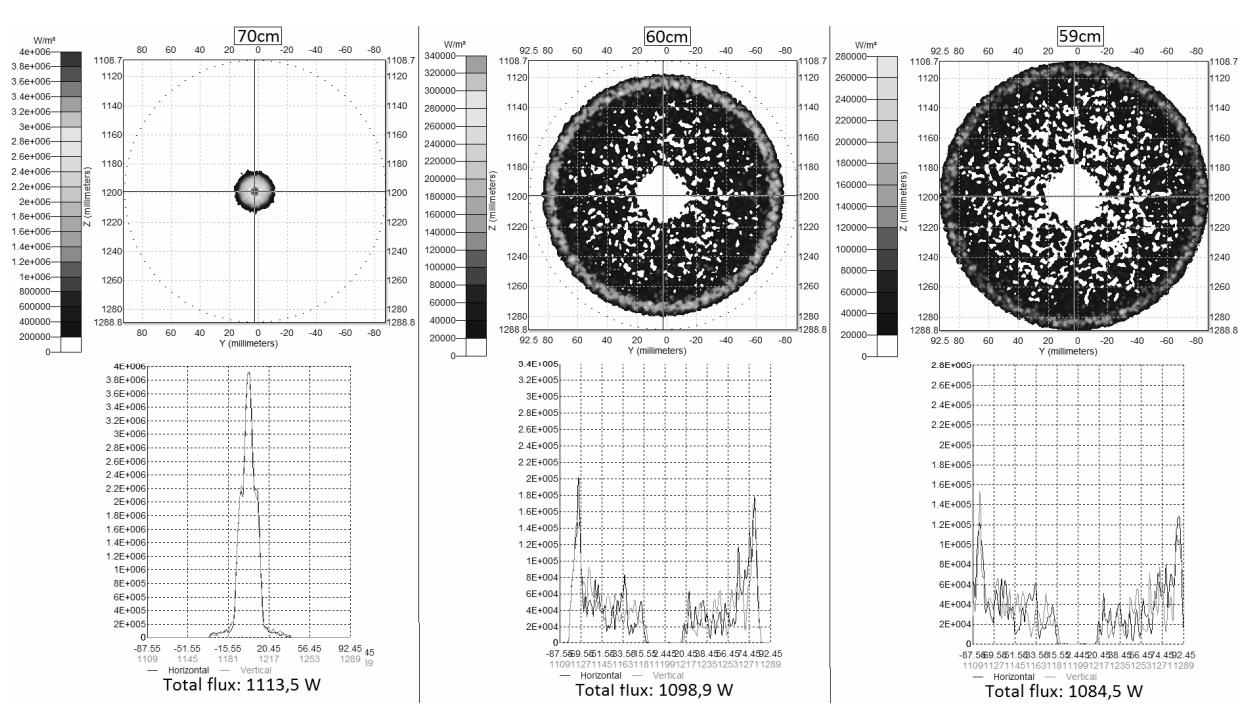

Rys. 6. Mapy i wykresy rozkładu natężenia promieniowania zaabsorbowanego przez odbiornik umieszczony w odległości: $70 \mathrm{~cm}, 60 \mathrm{~cm}$ i $59 \mathrm{~cm}$ od powierzchni lustra

Fig. 6. Irradiance maps and graphs of flux absorbed by heat exchanger placed in $70 \mathrm{~cm}, 60 \mathrm{~cm}$, $59 \mathrm{~cm}$ from mirror surface

Maksymalną całkowitą absorpcję natężenia światła w przykładach przedstawionych na rysunku 6 otrzymano w przypadku odbiornika umieszczonego w odległości $70 \mathrm{~cm}$ od powierzchni lustra. Jednak ułożenie to nie jest korzystne ze względu na rozkład natężenia - wszystkie promienie skupione są na bardzo małej powierzchni, co ze względu na wytrzymałość materiałową i wymianę ciepła $\mathrm{z}$ czynnikiem roboczym stanowiłoby poważny problem. Sprawdzono, że w odległości ok. $59 \mathrm{~cm}$ absorber pochłania całe promieniowanie z ogniska F2, przy czym rozkład natężenia w tym przypadku jest znacznie korzystniejszy. Należy mieć jednak na uwadze fakt, że koncentrator nie śledzi położenia słońca w sposób ciągły a w pewnych zadanych odstępach czasowych. Aktualnie, kąty elewacji i azymutu w badanej instalacji mogą być korygowane nie częściej niż co minutę. Dlatego wykonano również symulację układu dla absorbera umiejscowionego w odległości $60 \mathrm{~cm}$ od powierzchni lustra. W tym przypadku podobnie jak dla $59 \mathrm{~cm}$ natężenie światła jest wysokie, ale powierzchnia absorbera nie jest całkowicie zapełniona - pozostaje pierścień o szerokości ok. $1 \mathrm{~cm}$. Jest to obszar, który może zostać wykorzystany w przypadku, gdy ognisko będzie „uciekało" na skutek chwilowego braku śledzenia położenia Słońca. Jednak w każdym z powyższych przypadków nie wychwycono całkowitego promieniowania odbijanego od powierzchni koncentratora, a jedynie część skupiającą się w ognisku F2. Ponadto, dla odbiornika odsuniętego od koncentratora o $59 \mathrm{~cm}$ i $60 \mathrm{~cm}$, widoczne jest, że promieniowanie nie pada na jego środek - powierzchnia ok. $12 \mathrm{~cm}^{2}$ jest niewykorzystana. Jest to spowodowane cieniem rzucanym przez sam odbiornik ciepła. 
$\mathrm{Na}$ rysunku 7 zaprezentowano z kolei mapy i rozkład natężenia promieniowania dla absorbera umieszczonego pomiędzy dwoma ogniskami tj. w odległościach 75, 76 i $77 \mathrm{~cm}$ od powierzchni lustra.
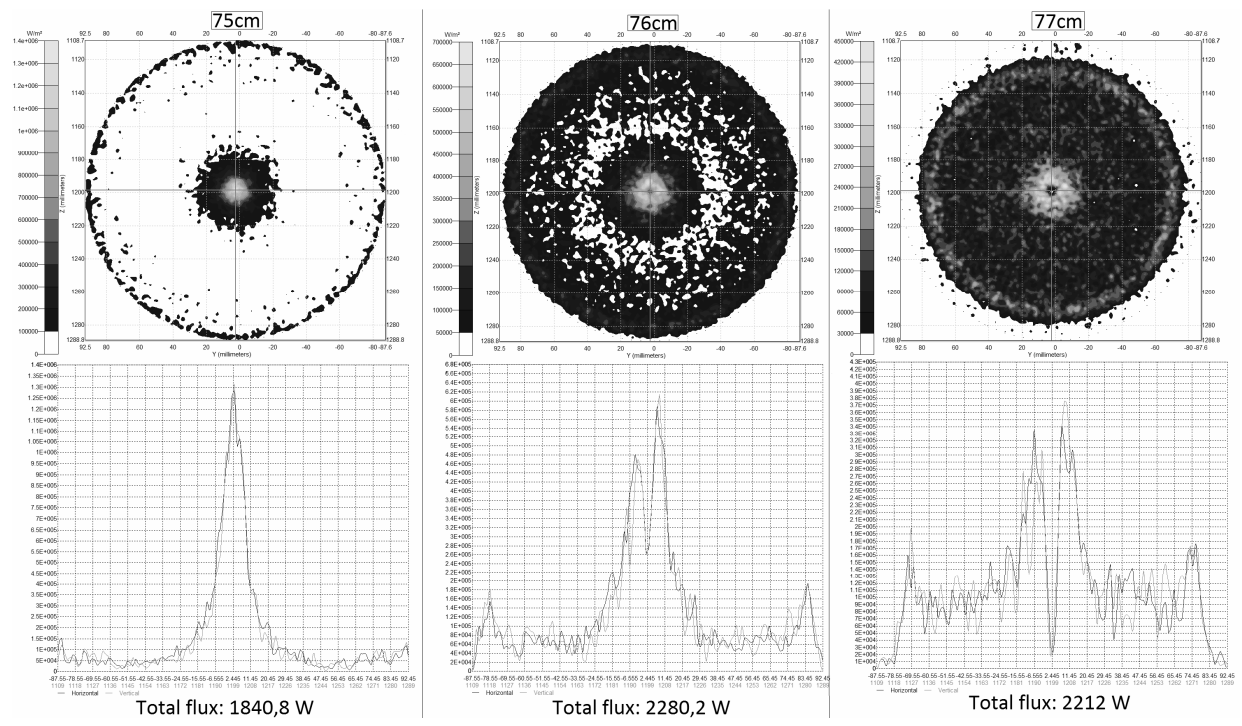

Rys. 7. Mapy i wykresy rozkładu natężenia promieniowania zaabsorbowanego przez odbiornik umieszczony w odległości: $75 \mathrm{~cm}, 76 \mathrm{~cm}$ i $77 \mathrm{~cm}$ od powierzchni lustra

Fig. 7. Irradiance maps and graphs of flux absorbed by heat exchanger placed in $75 \mathrm{~cm}, 76 \mathrm{~cm}$, $77 \mathrm{~cm}$ from mirror surface

W przypadku absorbera odsuniętego od powierzchni lustra o odległość $75 \mathrm{~cm}$ pada na niego promieniowanie z ogniska F2 oraz część promieniowania odbitego od czaszy koncentratora. $\mathrm{W}$ tym przykładzie zaabsorbowane zostało ok. $40 \%$ promieniowania więcej niż w przypadku absorberów umiejscowionych w odległościach 59, 60 i $70 \mathrm{~cm}$ od powierzchni lustra. Jednak rozkład natężenia promieni jest podobny jak w przypadku odbiornika odsuniętego na odległość $70 \mathrm{~cm}$ tj. prawie całe promieniowanie skupione na powierzchni ok. $12 \mathrm{~cm}^{2}$. Najlepszy pod kątem zaabsorbowanej ilości promieniowania wynik otrzymano dla absorbera umieszczonego $\mathrm{w}$ odległości $76 \mathrm{~cm}$ od powierzchni lustra. W takim przypadku do powierzchni odbiornika dociera prawie całe promieniowanie odbite od koncentratora. Aby pojawiło się dodatkowe miejsce dla ogniska, które będzie się nieco przemieszczało na wskutek skokowego trybu śledzenia położenia Słońca, wykonano symulację w której absorber odsunięty jest o $77 \mathrm{~cm}$ od powierzchni lustra. W mapie rozkładu natężenia zaabsorbowanego promieniowania widać, że na zewnętrznej części absorbera pozostaje wolny pierścień o szerokości ok. $1 \mathrm{~cm}$. Ponadto, miejsce to okazało się być lepszym nie tylko ze względu na pozostawione wolne pole, ale również ze względu na roz- 
kład natężenia promieniowania na powierzchni absorbera. W przypadku odbiornika umiejscowionego bliżej talerza tj. w odległości $76 \mathrm{~cm}$ występuje bardzo duży pik na środkowej części absorbera o wielkość ok. $778 \mathrm{~kW} / \mathrm{m}^{2}$. Natomiast w przypadku odbiornika odsuniętego od lustra o dodatkowy centymetr (77 cm od powierzchni koncentratora) wielkość ta wynosi $429 \mathrm{~kW} / \mathrm{m}^{2}$, a rozkład natężenia promieniowania na powierzchni odbiornika jest bardziej równomierny. Na podstawie przeprowadzonych symulacji można więc wnioskować, że najkorzystniejszym rozwiązaniem jest umieszczenie odbiornika ciepła wysokotemperaturowego w odległości $77 \mathrm{~cm}$ od powierzchni lustra.

\section{Wnioski}

Ze względów finansowych symulacje komputerowe mają coraz większe znaczenie. Dzięki ich wykorzystaniu możliwe jest nie tylko odpowiednie zaprojektowanie instalacji, ale także znalezienie błędów konstrukcyjnych i zaproponowanie odpowiednich ulepszeń już istniejących układów. Ponadto wykorzystanie techniki śledzenia promieni pozwala na wyznaczenie wielkości, które w rzeczywistym układzie są czasem niemożliwe do zmierzenia.

Przeprowadzone symulacje komputerowe miały na celu przede wszystkim wyznaczenie miejsca, w którym powinien zostać umiejscowiony absorber promieniowania w rzeczywistej instalacji helioenergetycznej. Przy wyborze odpowiedniego usytuowania kierowano się ilością absorbowanego promieniowania oraz rozkładem natężenia światła na powierzchni absorbera, aby był on jak najbardziej równomierny ze względu na wytrzymałość materiału oraz efektywność wymiany ciepła z czynnikiem roboczym.

Otrzymane wyniki posłużą do dalszej pracy w projektowaniu instalacji wykorzystującej skoncentrowane promieniowanie słoneczne. Planowane jest zwłaszcza wykorzystanie tych danych do przeprowadzenia komputerowych symulacji przepływu czynnika wewnątrz odbiornika ciepła. Przedstawione w niniejszym artykule za pomocą wykresów dane posłużą jako warunki brzegowe drugiego rodzaju tj. Neumana, gdzie konieczne jest wprowadzenie rozkładu gęstości strumienia na powierzchni, a temperatura ścianki nie jest znana. Modelowanie to będzie przeprowadzane w oparciu o numeryczną mechanikę płynów tj. CFD (Computational Fluid Dynamics) w programie Ansys. Dopiero wtedy okaże się, który rozkład padającego promieniowania będzie najkorzystniejszy z punktu widzenia przekazu ciepła do medium roboczego. 


\section{Literatura}

[1] Filipowicz M., Wajss P., Tomski M., Szubel M., Sornek K, Gastoł M., Bożek E.: Wykorzystanie skoncentrowanego promieniowania słonecznego $\mathrm{w}$ warunkach polskich, Rynek Instalacyjny 12/2012, s.30-32.

[2] Gerardo Diaz, , Numerical simulations of evacuated - tube solar collectors, Solar Energy: Today and Tomorrow, School of Engineering, University of California, Merced, 2008.

[3] Zajkowski M., Metoda Monte Carlo w obliczeniach odbłyśników obrotowo symetrycznych o odbiciu równomiernie rozproszonym, Przegląd Elektrotechniczny, nr 4, 2003, s. 285-286

[4] Sawicki D., Wybrane problemy symulacji figury jasnych punktów z wykorzystaniem metody śledzenia promieni, Prace naukowe Politechniki Warszawskiej, Elektryka, 2007, s.4-10.

\section{RAY TRACING METHOD IN MODELING HIGH-TEMPERATURE HELIOS ENERGY SYSTEMS}

\section{S u m m a r y}

This article presents the results of computer simulations performed on the Department of Sustainable Energy in the Faculty of Energy and Fuels in The University of Science and Technology in Krakow. Results concern the Helios energy system that concentrates solar radiation. The installation consist of two focusing elements and the high temperature heat exchanger. Due to the fact that system generates two different focal points, the main purpose of the study was to determine the best location of the absorber. The amount of light energy absorbed by heat exchanger and intensity distribution of radiation on its surface (material strength) was taken into account. Ray tracing method which is usually used to create realistic images in computer graphics was used to simulate the system. The research are based on a modified by Monte Carlo algorithm method. It consists in the fact that all rays coming from the light source and located on the optical scene are traced and not only those that go to the observer (as it is in classical ray tracing). As a result of performed simulation maps and charts of intensity distribution of radiation absorbed by the surface of the heat exchanger were generated. The analyzes allowed to conclude that the best solution for described installation is to place the heat exchanger at a distance of $77 \mathrm{~cm}$ from mirror surface. Received data will be used in future studies as Neumann boundary conditions in the computer simulations based on the technique of computational fluid dynamics.

Keywords: ray tracing, solar radiation concentrator, concentrated light, TracePro, computer simulations

Przestano do redakcji: 19.12.2014 r.

Przyjęto do druku: 22.06.2015 r.

DOI:10.7862/rb.2015.32 